\title{
Benzoyl-methylpolyols from Croton species (Euphorbiaceae)
}

\author{
Pedro R. Barbosa, Miguel Fascio, Dirceu Martins, and Nidia F. Roque* \\ Departamento de Química Orgânica, Instituto de Química, Universidade Federal da Bahia \\ (UFBA), Campus Universitário de Ondina, Salvador, 40170-290, Bahia, Brazil \\ E-mail:nifroque@ufba.br
}

Dedicated to Professor Otto Richard Gottlieb

(received 28 Jan 04; accepted 01 Aug 04; published on the web 13 Aug 04)

\begin{abstract}
Three new benzoyl-methylpolyols were isolated from Croton betulaster and C. luetzelburgii (Euphorbiaceae). The planar structures were elucidated by NMR spectroscopy, including bidimensional analysis. This class of compounds was not previously reported from Croton species. The high oxygenated molecules could be derived from an oxidative degradation of a terpene precursor.
\end{abstract}

Keywords: Benzoyl-methylpolyols, Croton betulaster, Croton luetzelburgii, Euphorbiaceae

\section{Introduction}

The Chapada Diamantina, in Brazil, is a region with a very diversified flora, being many plants endemic species. Euphorbiaceae is one of the representative families of the region. ${ }^{1}$ Plants of the genus Croton, the second in species number of that family, are largely found in the region. It comprises 700 species, 400 of them occurring in Brazil. ${ }^{2}$ This work is part of a research aiming to know the chemical composition of some plant species from Chapada Diamantina, in Bahia State. Plants of the genus Croton biosynthesized mainly, as secondary metabolites, diterpenes ${ }^{3}$ and alkaloids. ${ }^{4}$ They also produced triterpenes, ${ }^{5}$ sesquiterpenes, monoterpenes, ${ }^{6}$ flavonoids ${ }^{7}$ and other metabolites. In a previous work we described the isolation of triterpenes from Croton betulaster ${ }^{8}$ and flavonoids from both C. betulaster and C. luetzelburgii ${ }^{9}$ but diterpenes and alkaloids were not found in these plants. Now, we describe three new benzoyl-methylpolyols isolated from Croton betulaster and C. luetzelburgii collected at Chapada Diamantina. This class of compounds were not previously reported from Croton species and from a preliminary bibliographic survey, from other Euphorbiaceae genus and, even, from other plant families. 


\section{Results and Discussion}

The three compounds 1-3 were isolated from dichloromethane extracts of leaves. Compound 1 was isolated from Croton betulaster and compounds 2 and 3 from Croton luetzelburgii. Compound 1 was isolated as a crystalline solid. The ${ }^{1} \mathrm{H}$ NMR spectrum of 1 showed two singlets at $\delta 1.37$ and 1.38 relative to three hydrogens each of them, (Table 1) suggesting the presence of two methyl groups at oxygenated carbon. A multiplet at $\delta 4.14$, a large singlet at $\delta 4.22$ and a large doublet at $\delta 4.84(6.3 \mathrm{~Hz})$ suggested the presence of three oxygenated $\mathrm{CH}$ groups. The two double doublets at $\delta 4.44(11.3$ and $6.7 \mathrm{~Hz})$ and $4.52(11.3$ and $3.4 \mathrm{~Hz})$ suggested an oxygenated $\mathrm{CH}_{2}$ in the molecule. In the aromatic region of the ${ }^{1} \mathrm{H}$ NMR spectrum of 1 there were signals ascribed to one phenyl and one para substituted phenyl group (Table 1). Four large singlets, that disappear after addition of $\mathrm{D}_{2} \mathrm{O}$, suggested the presence of four hydroxyls. These data are confirmed by the formation of a tetra acetyl derivative (1a).

The ${ }^{13} \mathrm{CNMR}$ spectra (BBD and DEPT) of 1 showed the presence of 17 signals, two $\mathrm{CH}_{3}$, one $\mathrm{CH}_{2}$, eight $\mathrm{CH}$ and six signals assigned to unprotonated carbon atoms (Table 2). All the aliphatic carbons except the methyl groups are oxygenated. The signals at $\delta 167.0$ and 172.2 ascribed to carboxyl aromatic esters suggested the presence of a benzoyl and p-hydroxybenzoyl groups esterifying a polyol chain. The HMQC spectrum showed the ${ }^{1} \mathrm{~J}$ correlations between carbon and hydrogen (Tables 1 and 2).

The planar structure of the molecule was determined by the long range correlations between carbon and hydrogen. A HMBC spectrum established the position of the benzoyl and phydroxybenzoyl esters in the chain. The correlation between the signal at $\delta 167.0$ corresponding to the benzoyl group with the hydrogen signals at $\delta 4.52$ and 4.44 located this group at $\mathrm{C}-1$. The observation of a correlation between the signal at $\delta 78.9(\mathrm{C}-4)$ and the methyl signals $(\delta 1.37$ and 1.38 ) confirmed the assignment for $\mathrm{C}-4$. The $\mathrm{H}-4$ signal $(\delta 4.22)$ showed a correlation with $\delta$ 172.2 assigned to the p-hydroxybenzoyl carboxyl. Therefore, the planar structure of 1 was defined as 1-benzoyloxy-4-p-hydroxybenzoyloxy-2,3,5-trihydroxy-5-methylhexane (Figure 1).

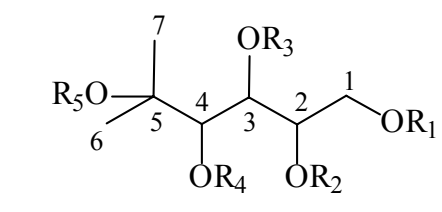

1: $\mathrm{R}_{1}=\mathrm{A}, \mathrm{R}_{4}=\mathrm{B}, \mathrm{R}_{2}=\mathrm{R}_{3}=\mathrm{R}_{5}=\mathrm{H}$
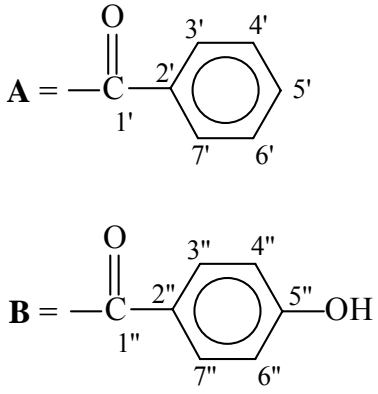

Figure 1. Structure of compound 1. 
Compounds 2 and 3 were isolated as amorphous gums and their ${ }^{1} \mathrm{H}$ NMR spectra showed the same spectral features as that of $\mathbf{1}$. Compound 2 has ${ }^{1} \mathrm{H}$ and ${ }^{13} \mathrm{C}$ NMR signals that could be assigned to two benzoyl and one p-hydroxy benzoyl groups (Tables 1 and 2). The ${ }^{1} \mathrm{H}$ NMR spectrum of 2 also showed a large doublet at $\delta 6.72$ and a double triplet at $\delta 6.37$ that was assigned to hydrogens of a double bond neighbouring a $\mathrm{CH}$. and a $\mathrm{CH}_{2}$ groups respectively. This spectrum also exhibited a singlet at $\delta 5.25$. The ${ }^{13} \mathrm{C}$ NMR spectrum display 21 signals that are in agreement with the presence of the mentioned groups, in an oxygenated 5-methylhex-2-ene chain. The carbon multiplicities and the ${ }^{1} \mathrm{~J}$ correlations were established by a DEPT and a HMQC spectrum respectively. As in 1, the positions of the esters were established by the observation of long range correlations in a HMBC spectrum. Observation of a long range coupling between the carboxyl of the p-hydroxybenzoyl group $(\delta 167.3)$ and $\mathrm{H}-4(\delta 5.25)$ located this group at C-4. Other correlations (Table 2) confirmed the planar structure of 2, as 1,5dibenzoyloxy-4-p-hydroxybenzoyloxy-5-methylhex-2-ene (Figure 2).

The ${ }^{1} \mathrm{H}$ NMR spectrum of 3 showed signals compatible with the presence of one benzoyloxy, one p-hydroxybenzoyloxy and one ethoxyl group $(\delta 1.17 \mathrm{t}, 3.44 \mathrm{~m}$ and $3.34 \mathrm{~m}$ ) in the molecule (Table1). The multiplet at $\delta 2.55$ and the doublets at $\delta 1.24$ and 1.22 indicated that C-5, in 2, is not oxygenated. The large singlet $(2 \mathrm{H})$ at $3.67 \delta$ suggested the presence of a hydroxyl group at $\mathrm{C}-1$. The ${ }^{13} \mathrm{C}$ NMR (BBD and DEPT) spectra showed the presence of 19 signals, three of them from methyl groups, in agreement with the signals observed in the ${ }^{1} \mathrm{H}$ NMR spectrum. A HMQC spectrum established the $\mathrm{CH}$ correlations. The chemical shift and long range coupling of $\mathrm{H}-2$ suggested that the ethoxy group is located at C-2 (Table 2). The long range couplings showed, by means of the HMBC spectrum, between $\mathrm{H}-4$ and the carboxyl of the p-hydroxybenzoyloxy group established the structure of $\mathbf{3}$ as 3-benzoyloxy-4-p-hydroxybenzoyloxy-2-ethoxy-1-hydroxy-5methylhexane (Figure 2).

Further experiments will be done to establish the stereochemistry of compounds 1-3 that probably belong to a new class of secondary metabolites of plants.

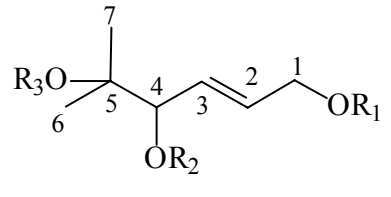

2: $\mathrm{R}_{1}=\mathrm{R}_{3}=\mathrm{A}, \mathrm{R}_{2}=\mathrm{B}$
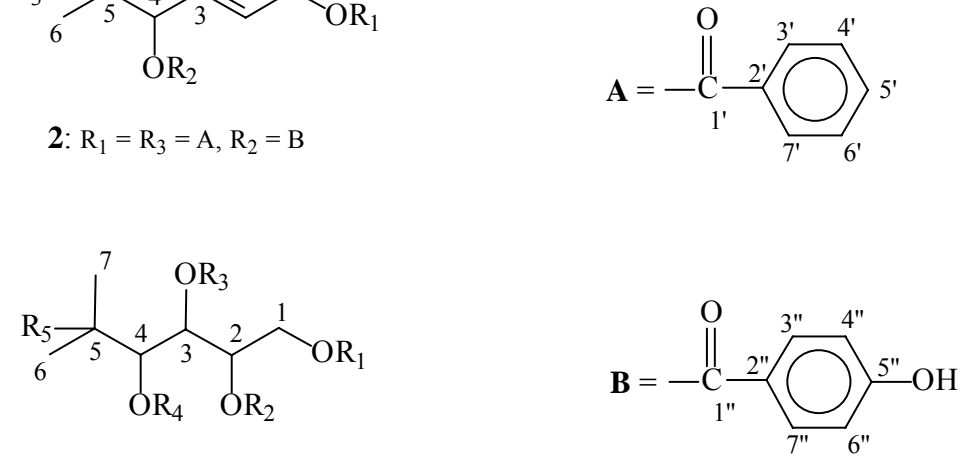

$$
\text { 3: } \mathrm{R}_{1}=\mathrm{R}_{5}=\mathrm{H}, \mathrm{R}_{2}=\mathrm{CH}_{2} \mathrm{CH}_{3}, \mathrm{R}_{3}=\mathrm{A}, \mathrm{R}_{4}=\mathrm{B}
$$

Figure 2. Structures of compounds 2 and 3. 
Table 1. ${ }^{1} \mathrm{H}$ NMR of 1-3 (500 MHz): $\delta$, multiplicity and coupling constants $J[\mathrm{~Hz}]$

\begin{tabular}{|c|c|c|c|}
\hline & 1* & $2^{+}$ & $3^{+}$ \\
\hline 1 & 4. 52 (dd; 11.3; 3.4); 4.44 (dd; 11.3; & $4.98(d d ; 6.3 .1 .3)$ & 3.67 \\
\hline 2 & $4.14(m)$ & $6.37(d t ; 16.0 .6 .4)$ & 3.67 \\
\hline 3 & $4.84(d l)$ & $6.72(d l ; 16.0)$ & $4.38(d .4 .6)$ \\
\hline 4 & $4.22(\mathrm{sl})$ & $5.25(s)$ & $5.24(d .4 .6)$ \\
\hline 5 & _- & - & $2.55(m)$ \\
\hline 6 & $1.37^{\mathrm{a}}(\mathrm{s})$ & $1.55^{\mathrm{a}}(\mathrm{s})$ & $1.24^{\mathrm{a}}(d ; 6.6)$ \\
\hline 7 & $1.38^{\mathrm{a}}(\mathrm{s})$ & $1.53^{\mathrm{b}}(\mathrm{s})$ & $1.22^{\mathrm{a}}(d ; 6.9)$ \\
\hline $1^{\prime}$ & - & - & - \\
\hline $2^{\prime}$ & - & - & - \\
\hline $3^{\prime}$ & $8.04(d d ; 7.8 ; 1.1)$ & $8.09(d d ; 1.2 ; 7.9)$ & $8.12(d ; 7.6)$ \\
\hline 4 & $7.52(t ; 7.8)$ & $7.45(t ; 7.9)$ & $7.47(t ; 7.6)$ \\
\hline $5^{\prime}$ & $7.64(t t ; 7.8 ; 1.1)$ & $7.58(t t ; 7.9 ; 1.2)$ & $7.60(t ; 7.6)$ \\
\hline $6^{\prime}$ & $7.52(t ; 7.8)$ & $7.45(t ; 7.9)$ & $7.47(t ; 7.6)$ \\
\hline $7^{\prime}$ & $8.04(d d ; 7.8 ; 1.1)$ & $8.09(d d ; 1.2 ; 7.9)$ & $8.12(d .7 .6)$ \\
\hline $1^{\prime \prime}$ & - & - & - \\
\hline $2^{\prime \prime}$ & - & - & - \\
\hline 3" & $7.54(d ; 8.5)$ & $7.42(d ; 9.0)$ & $7.34(d ; 8.5)$ \\
\hline $4 "$ & $7.13(d ; 8.5)$ & $7.10(d ; 9.0)$ & $7.13(d ; 8.5)$ \\
\hline $5^{\prime \prime}$ & - & - & - \\
\hline 6" & $7.13(d ; 8.5)$ & $7.10(d ; 9.0)$ & $7.13(d ; 8.5)$ \\
\hline $7^{\prime \prime}$ & $7.54(d ; 8.5)$ & $7.42(d ; 9.0)$ & $7.34(d ; 8.5)$ \\
\hline $1^{\prime \prime \prime}$ & - & - & $3.44(m)$ e 3.34 \\
\hline $2 " \prime$ & - & - & $1.17(t ; 6.9)$ \\
\hline $3^{\prime \prime \prime}$ & - & $8.13(d d ; 1.2 ; 7.7)$ & - \\
\hline $4^{\prime \prime \prime}$ & - & $7.50(t ; 7.7)$ & - \\
\hline $5^{\prime \prime \prime}$ & - & $7.63(t t ; 7.7 ; 1.2)$ & - \\
\hline $6^{\prime \prime \prime}$ & - & $7.50(t ; 7.7)$ & - \\
\hline 7"' & - & $8.13(d d ; 1.2 ; 7.7)$ & - \\
\hline
\end{tabular}

* acetone- $\mathrm{d}_{6}$.

${ }^{+} \mathrm{CDCl}_{3}$. 
Table 2. ${ }^{13} \mathrm{C}$ NMR and HMBC data of 1-3 (125 MHz): $\delta$ and multiplicity

\begin{tabular}{|c|c|c|c|c|c|c|}
\hline & $\begin{array}{c}1 \\
13 \mathrm{C} \\
{ }^{13}\end{array}$ & HMBC & $\begin{array}{c}2 \\
{ }^{13} \mathrm{C} \\
\end{array}$ & HMBC & $\begin{array}{c}3 \\
{ }^{13} \mathrm{C} \\
\end{array}$ & $\mathrm{HMBC}$ \\
\hline 1 & $67.1\left(\mathrm{CH}_{2}\right)$ & $\mathrm{H}-3$ & $65.3\left(\mathrm{CH}_{2}\right)$ & & $62.9\left(\mathrm{CH}_{2}\right)$ & \\
\hline 2 & $74.3(\mathrm{CH})$ & $\mathrm{H}-1$ & $123.9(\mathrm{CH})$ & $\mathrm{H}-1$ & $74.1(\mathrm{CH})$ & $\mathrm{H}-3$ \\
\hline 3 & $74.9(\mathrm{CH})$ & & $133.0(\mathrm{CH})$ & $\mathrm{H}-3^{\prime \prime}, \mathrm{H}-1$ & $82.9(\mathrm{CH})$ & $\mathrm{H}-1$ or $\mathrm{H}-2$ \\
\hline 4 & $78.9(\mathrm{CH})$ & H-6 e H-7 & $78.9(\mathrm{CH})$ & H-6, H-7 & $77.0(\mathrm{CH})$ & H-6, H-7 \\
\hline 5 & $72.7(\mathrm{C})$ & H-4, H-6 e H-7 & $71.6(\mathrm{C})$ & H-6, H-7 & $30.2(\mathrm{CH})$ & H-6, H-7, H-4 \\
\hline 6 & $26.7^{\mathrm{a}}\left(\mathrm{CH}_{3}\right)$ & $\mathrm{H}-4$ & $26.4^{\mathrm{a}}\left(\mathrm{CH}_{3}\right)$ & $\mathrm{H}-4$ & $17.4^{\mathrm{a}}(\mathrm{CH} 3)$ & $\mathrm{H}-7$ \\
\hline 7 & $26.2^{\mathrm{a}}\left(\mathrm{CH}_{3}\right)$ & $\mathrm{H}-4$ & $26.2^{\mathrm{a}}\left(\mathrm{CH}_{3}\right)$ & $\mathrm{H}-4$ & $18.7^{\mathrm{a}}\left(\mathrm{CH}_{3}\right)$ & H-6 \\
\hline $1^{\prime}$ & $167.0(\mathrm{C})$ & H-1, H-3' & $166.4(\mathrm{C})$ & H-1, H-3' & $166.0(\mathrm{C})$ & H-3' \\
\hline $2^{\prime}$ & $131.5(\mathrm{C})$ & & $130.2(\mathrm{C})$ & & $129.1(\mathrm{C})$ & $\mathrm{H}-5^{\prime}$ \\
\hline $3^{\prime}$ & $130.4(\mathrm{CH})$ & & $128.7^{\mathrm{b}}(\mathrm{CH})$ & & $129.6(\mathrm{CH})$ & H-5' \\
\hline $4^{\prime}$ & $129.4^{\mathrm{b}}(\mathrm{CH})$ & & $129.9^{\mathrm{c}}(\mathrm{CH})$ & & $128.2^{\mathrm{b}}(\mathrm{CH})$ & \\
\hline $5^{\prime}$ & $133.9(\mathrm{CH})$ & & $133.0(\mathrm{CH})$ & H-3' & $133.2(\mathrm{CH})$ & H-3' \\
\hline $6^{\prime}$ & $129.4^{\mathrm{b}}(\mathrm{CH})$ & & $129.9^{\mathrm{c}}(\mathrm{CH})$ & & $128.2^{\mathrm{b}}(\mathrm{CH})$ & \\
\hline $7^{\prime}$ & $130.4(\mathrm{CH})$ & & $128.7^{\mathrm{b}}(\mathrm{CH})$ & & $129.6(\mathrm{CH})$ & $\mathrm{H}-5^{\prime}$ \\
\hline $1 "$ & $172.2(\mathrm{C})$ & $\mathrm{H}-4$ & $167.3(\mathrm{C})$ & $\mathrm{H}-4$ & $168.2(\mathrm{C})$ & $\mathrm{H}-4$ \\
\hline $2^{\prime \prime}$ & $141.3(\mathrm{C})$ & $\mathrm{H}-3, \mathrm{H}-4^{\prime \prime}, \mathrm{H}-6^{\prime \prime}$ & $134.6(\mathrm{C})$ & $\mathrm{H}-4^{\prime \prime}$ & $136.6(\mathrm{C})$ & $\mathrm{H}-4^{\prime \prime}$ \\
\hline $3 "$ & $129.0^{\mathrm{b}}(\mathrm{CH})$ & & $127.7(\mathrm{CH})$ & & $128.0(\mathrm{CH})$ & \\
\hline $4 "$ & $121.9(\mathrm{CH})$ & & $121.6(\mathrm{CH})$ & & $121.3(\mathrm{CH})$ & \\
\hline $5 "$ & $150.9(\mathrm{C})$ & $\mathrm{H}-3^{\prime \prime}, \mathrm{H}-4^{\prime \prime}$ & $149.9(\mathrm{C})$ & $\mathrm{H}-3^{\prime \prime}, \mathrm{H}-4^{\prime \prime}$ & $149.7(\mathrm{C})$ & $\mathrm{H}-4^{\prime \prime}, \mathrm{H}-3^{\prime \prime}$ \\
\hline $6 "$ & $121.9(\mathrm{CH})$ & & $121.6(\mathrm{CH})$ & & $121.3(\mathrm{CH})$ & \\
\hline $7 "$ & $129.0^{\mathrm{b}}(\mathrm{CH})$ & & $127.7(\mathrm{CH})$ & & $128.0^{\mathrm{b}}(\mathrm{CH})$ & \\
\hline $1 " '$ & & & $165.9(\mathrm{C})$ & $\mathrm{H}-3^{\prime \prime \prime}$ & $64.8\left(\mathrm{CH}_{2}\right)$ & \\
\hline $2^{\prime \prime \prime}$ & & & $129.0(\mathrm{C})$ & & $15.0\left(\mathrm{CH}_{3}\right)$ & $\mathrm{H}-2^{\prime \prime \prime}$ \\
\hline $3^{\prime \prime \prime}$ & & & $128.4^{\mathrm{b}}(\mathrm{CH})$ & & & \\
\hline 4"' & & & $129.7^{\mathrm{c}}(\mathrm{CH})$ & & & \\
\hline $5 " '$ & & & $133.7(\mathrm{CH})$ & $\mathrm{H}-3^{\prime \prime \prime}$ & & \\
\hline 6"' & & & $129.7^{\mathrm{c}}(\mathrm{CH})$ & & & \\
\hline $7^{\prime \prime \prime}$ & & & $128.4^{\mathrm{b}}(\mathrm{CH})$ & & & \\
\hline
\end{tabular}

* acetone- $\mathrm{d}_{6}$.

${ }^{+} \mathrm{CDCl}_{3}$. 


\section{Conclusions}

These compounds (1-3) are described for the first time from Croton plants and as far as we know from other Euphorbiaceae genus and, even, from other families. The biosynthetic paths of these methylpolyols compounds could be suggested to occur in two or three ways, methylation and reduction of carbohydrate molecules, degradation and reduction of 3-dehydroshikimate or oxidative degradation of terpenes. The absence of diterpenes, compounds with a high occurrence in Euphorbiaceae plants, in Croton betulaster and C. luetzelburgii associated with the presence of the benzoyl-methylpolyols compounds could suggest that these molecules are biosyntheticaly derived from the degradation process of diterpene precursors. Some hydroxyditerpenes occur in Euphorbiaceae plants as benzoyl esters. ${ }^{10}$ The occurrence of methylpolyol compounds confirms the previous observation that the chemistry of Euphorbiaceae is among the most diverse of all plant families, being many of the most unusual classes of compounds found only in this family. ${ }^{11}$

\section{Experimental Section}

General Procedures. Melting point was determined with a hot-stage apparatus. Column chromatography were performed on silica gel (Merck 60,70-230 mesh). NMR spectra were recorded on a Bruker 500 spectrometer $\left(11.7\right.$ Tesla, $500 \mathrm{MHz}$ for ${ }^{1} \mathrm{H}$ and $125 \mathrm{MHz}$ for $\left.{ }^{13} \mathrm{C}\right)$. Chemical shifts $\delta$ (in ppm) are given from internal $\mathrm{CHCl}_{13}$ ( $\delta 7.26$ for $\left.{ }^{1} \mathrm{H} \mathrm{NMR}\right)$ and $\mathrm{CDCl}_{3}(\delta$ 77.0 for ${ }^{13}$ C NMR).

Plant material. Leaves of Croton betulaster Müll. Arg. were collected at Palmeiras, Chapada Diamantina, Bahia, Brazil, in June 1997, while leaves of C. luetzelburgii Pax \& Hoffm were collected in Lençois, Chapada Diamantina in October 2000. Maria Lenise da S. Guedes from Instituto de Biologia, Universidade Federal da Bahia identified the vegetable materials and voucher specimens have been deposited at Alexandre Leal Costa Herbarium, UFBA under the numbers 031762 and 048659 respectively.

Extraction and isolation. The ground air dried leaves $(600 \mathrm{~g})$ of Croton betulaster were successively extracted with hexane and dichloromethane After solvent evaporation, the dichloromethane extracted $(45.0 \mathrm{~g})$ was applied to a silica gel column and eluted with gradient mixtures of hexane and ethyl acetate. The less polar fractions gave flavonoids ${ }^{9}$ and the more polar fractions was submitted to another silica gel column chromatography eluted with gradient mixtures of $\mathrm{CHCl}_{3}$ and $\mathrm{MeOH}$ to give $1(20 \mathrm{mg})$.

The ground air dried leaves (320 g) of Croton lutzelburguii were extracted with ethanol After partial removal of the solvent the extract was dissolved in $\mathrm{EtOH}-\mathrm{H}_{2} \mathrm{O}(9: 1)$ and then fractionated against hexane and dichloromethane. The dichloromethane extract $(30 \mathrm{~g})$ was submitted to a silica gel column chromatography eluted with gradient mixtures of hexane and ethyl acetate to give flavonoids ${ }^{9}$, compound $\mathbf{2}(5 \mathrm{mg})$ and compound $3(15 \mathrm{mg})$. The compounds were purified by 
silica gel column and thin layer chromatographies eluted with gradient mixtures of hexane, dichloromethane and $\mathrm{MEOH}$.

1-Benzoyloxy-4-para-hydroxybenzoyloxy-2-3-5-trihydroxy-5-methylhexane (1). Colourless crystals, mp 138.5-139.5 ${ }^{\circ} \mathrm{C}$, acetone. ${ }^{1} \mathrm{H}$ and ${ }^{13} \mathrm{C}$ NMR data see Tables 1 and 2.

1-Benzoyloxy-4-para-acetoxybenzoyloxy-2-3-5-triacetoxy-5-methylhexane (1a). $3 \mathrm{mg}$ of 1 was dissolved in pyridine and acetic anhydride and dimethylaminopyridine were added. The solution was kept over night and elaborated as usual, to give 1a $(98 \%)$, as a colourless gum. ${ }^{1} \mathrm{H}$ NMR, $300 \mathrm{MHz}, \mathrm{CDCl}_{3}, \delta(\mathrm{m}, \mathrm{H}): 1.63$ (s, 3H), 1.69 (s,3H), 2.01 (s.3H), 2.04 (s.3H), 2.14 (s.3H), 2.20 (s.3H), $4.4(\mathrm{~m}, 2 \mathrm{H}), 5.5(\mathrm{~m}, 2 \mathrm{H}), 6.10(\mathrm{~d}, 1 \mathrm{H}) 7.12(\mathrm{~d}, 2 \mathrm{H}), 7.43(\mathrm{~d} \mathrm{2H}) 7.46(\mathrm{t}, 2 \mathrm{H})$. ${ }^{13} \mathrm{C}$ NMR, $75 \mathrm{MHz}, \mathrm{CDCl}_{3}, \delta:$ 20.5, 20.7, 20.9, 22.1, 23.1, 23.4, 62.1, 72.3, 72.8, 75.6, 80.2, $121.4,128.4,128.5,129.7,130.8,133.2,133.9,150.3,166.0,166.3,169.4,169.9,170.0,170.1$.

1,5-Dibenzoyloxy-4-para-hydroxybenzoyloxy-5-methylhex-2-ene (2). Colourless gum. ${ }^{1} \mathrm{H}$ and ${ }^{13} \mathrm{C}$ NMR data see Tables 1 and 2.

3-Benzoyloxy-4-para-hydroxybenzoyloxy-2-ethoxy-1-hydroxy-5-methylhexane(3).

Colourless gum. ${ }^{1} \mathrm{H}$ and ${ }^{13} \mathrm{C}$ NMR data see Tables 1 and 2.

\section{Acknowledgements}

The authors are grateful to FINEP and CNPq for the financial support and scholarships to NFR and PRB, to Maria Lenise da S. Guedes for the plant material identification. The authors are also grateful to CENAUREM, UFC and to Instituto de Química, UNESP for NMR spectra.

\section{References}

1. Stannard, B. L., Ed.; Flora of the Pico das Almas; Royal Botanic Gardens: Kew, Great Britain, 1995 p 853.

2. Bressan, F. A.; Bernardes, M. S.; Campos, E. B.; Morais, A. A. $21^{a}$ Reunião Anual da Sociedade Brasileira de Química, Poços de Caldas, MG. 1998, PN-016.

3. Puebla, P.; López, J. L.; Guerrero, M.; Carrón, R.; Martín, M. L.; Román, L. S.; Feliciano, A. S. Phytochemistry 2003, 62, 551.

4. Charris, J.; Dominguez, J.; De La Rosa, C.; Caro, C. Biochemical Systematics and Ecology, 2000, 28, 795.

5. Maciel, m. A. M.; Pinto, A. C.; Brabo, S. N.; Silva, M. N. Terpenoids from Croton cajucara, Phytochemistry 1998, 49, 823.

6. Martins, A. P.; Salgueiro, L. R.; Goncalves, M. J.; Vila, R.; Tomi, F.; Adzet, T.; Cunha, A. P.; Canigueral, S.; Casanova, J. Planta Medica 2000, 66, 647.

7. Guerrero, M. F.; Puebla, P.; Carrbon, R.; Martin, M. L.; Roman, L. S. Journal of Pharmacy and Pharmacology 2002, 54, 1373. 
8. Barbosa, P. R.; Fascio, M.; Martins, D.; Guedes, M. L. S.; Roque, N. F. Biochemical Systematics and Ecology 2003, 31, 307.

9. Barbosa, P. R. PhD Thesis, Instituto de Química, UFBA, Salvador, 2003.

10. Ferreira,A. M. V. D.; Carvalho, L. H. M.; Carvalho, M. J. M.; Serquiera,M. M.; Silva, A. M. S. Phytochemistry 2002, 61, 373.

11. Seigler, D. S. Annals of the Missouri Botanical Garden 1994, 81, 380. 